\title{
The psychological and pedagogical model of training in the educational space for the agricultural sector
}

\author{
Margarita Khutornaya ${ }^{1, *}$, Andrey Zlobin ${ }^{1}$ \\ 1Voronezh State University of Engineering Technologies, 19, Revolution Avenue, 394036, Voronezh, \\ Russia
}

\begin{abstract}
The article discusses the issues of preparing a student for professional activities in the context of digitalization. Analyzed are pedagogical technologies focused on the implementation of scientific research and aimed at the most effective and rational methods of training, taking into account labor market trends. It describes in detail the integration into the educational space of interactive learning and the effectiveness of its application. The author proposes a theoretical psychological and pedagogical model, which includes blocks: interactive learning, positive factors (contributing to the development of positive educational motivation), negative factors (which impede the development of positive motivational activity), "I-image", development of needs, basic properties of the nervous system. More attention is paid to stress resistance, as one of the individual and personal determinants that determine the demand for labor in the agricultural sector.
\end{abstract}

\section{Introduction}

Nowadays modeling in pedagogy has been studied most recently. Authors such as N.K. Sergeeva, V.S. Ilyina, N.M. Borytko, Yu.O. Delimova and a number of other researchers emphasize the main dominant in modeling on the integrity of a process or phenomenon, and the information directly related to them is important. The components of the model should be structurally interconnected [1,2]. The formation of a competency-based approach in teaching students sets goals that can initially be realized in creating a theoretical psychological and pedagogical model.

M. V. Yadrovskaya proposes to analyze some experience of applying this procedure to solve various problems and obtain results. The author assumes that the model cannot be perfect, since there is a subjectivity of opinions on this subject, but classifications often apply are subject to. And they should be based on the main pedagogical goals: educational, educational, developing. There are ways to develop a model: observation and analysis. Therefore, pedagogical models are used to study an object in the educational process for its explanation, refinement, or as a means to influence the construction and functioning of a pedagogical object based on its analysis of its model representation [3].

\footnotetext{
${ }^{*}$ Corresponding author: mlh10@yandex.ru
} 
Foreign authors especially actively studied modeling in pedagogy at the beginning of the 2000 s and characterized it as often used [4].

\section{Literature review}

The theoretical psychological and pedagogical model can correlate with special software, among which the most common are: Statistica, Lisrel, AMOS based on SPSS, EQS, Mplus, SAS and also programs with unhindered access: Lavaan and OpenMx. The relevance of the topic remains unquestionable, since psychological and pedagogical developments focused on the transformation of traditional teaching are insufficiently represented in the modern educational space and new ways of constructing the educational process and teaching technology are not algorithmic.

On December 26, 2019, a meeting of the State Council was held on the state agrarian policy. The agenda included issues of effective agricultural production and rural development. V.V. Putin ordered by September 1, 2020 to update the list of specialties in vocational education in the field of agriculture. It was proposed to update the list of professions and specialties in the preparation of higher vocational education and STR.

To improve the quality of training, in order to meet their new requirements for digitalization, it is necessary to amend the Federal State Educational Standard, educational programs, and professional development programs.

Also, the head of state instructed Rosmolodezh to prepare, together with the Ministry of Labor, the Ministry of Agriculture, and the Ministry of Education and Science with the participation of the Russian Union of Rural Youth, proposals for the development of a project for the "Personnel for the Village" program, including the formation of teams of young specialists for implementing social projects in the village.

The beginning of the digital revolution with the advent of the Internet has changed not only the economy, but modern life in general. For the full development of the economy and social structures, national projects have been created, one of which includes the active development of the digital economy.

This direction has its advantages and disadvantages. The advantages of the dynamics of the digital economy include:

1) growth trends in labor productivity;

2) the competitiveness of organizations in the labor market;

3 ) the emergence of demand for promising professions;

4) optimization of production costs;

5) reduction of social inequality.

Disadvantages are: this is the risk of unemployment associated with the departure of a number of professions from the labor market. Therefore, the formation of a full-fledged digital environment implies the provision of highly qualified competent personnel during digitalization in the agricultural sector.

The motivation of students to study, the formation of professional self-awareness, the use of innovative teaching technologies - all these are necessary factors for improving the training of future specialists for the agro-industrial complex. Innovative searches of modern pedagogy continue, at different levels of education from undergraduate to graduate school, teaching technologies are developed and tested [5].

Technology - the application of scientific knowledge, a set of methods aimed at obtaining a practical result, at a qualitative change in the object.

The term "educational technology" first appeared in Russian pedagogy in the 1960s. and meant the process of planning and organizing the pedagogical process with a guaranteed result [6]. The science of pedagogy throughout its existence conducted a scientific search for subject-subject interaction and improved its methods and means [7]. For a long time, 
traditional means and teaching methods have been used, but the dynamism of economic and social processes focuses on the production of more advanced and relevant forms of teaching. So pedagogical practice has accumulated many invariant, universally significant features of didactic developments, but the results of their application were not always unambiguous. Therefore, pedagogical technologies continue to improve, taking into account global educational trends.

Pedagogical technology - a set of methods aimed at obtaining a result in the educational space [8].

Founder of scientific pedagogy Ya.A. Comenskiy expressed the idea of technologizing the learning process. He belongs to the term "technicality" in relation to training, that is, he had in mind the practicability of the knowledge gained.

Researchers offer many definitions of the described process. The most correct, in our opinion, definition of pedagogical technology is provided by M.V. Clarin [9]. In his opinion, pedagogical technology means a system of totality and the functioning of all personal, instrumental, and methodological tools used to achieve pedagogical goals.

The modern educational space implies the use of various educational technologies and a fairly wide pedagogical arsenal: these are technologies of active teaching methods, design, health-saving, self-development technologies, advanced learning technologies, "learning in cooperation" technology.

Modern pedagogical technologies implement scientific research aimed at the most effective and rational methods of training, taking into account labor market trends.

It is obvious that social and economic updates that have been going on for some time within social systems and in society as a whole directly affect the educational space. It should correspond to the dynamics of transformations and be based on progressive and innovative approaches to the study of disciplines. In accordance with the foregoing, curricula are formed, teaching plans are compiled that expand their boundaries in accordance with the increase in the information field and the necessary practical orientation; innovative psychological and pedagogical technologies are developed and applied.

The merit of modern psychological and pedagogical technologies lies in the fact that knowledge is based on the advantage of teamwork, which is based on active cooperation, subject-subject relations, as well as research and experimental work with various sources of information. This contributes to the development of independent critical thinking and increases the level of competence.

Consider the use of psychological and pedagogical technologies in the educational process, in which the student has a real chance, using personal potential, individual abilities, to carry out practice-oriented training and achieve high results in wide areas of knowledge. Innovative technologies are many methods, the vector of which is aimed at a practical result, but it is necessary to use completely new, modern communication and information achievements in the context of a competency-based approach [10]. Today's times of changing outdated education paradigms imply the improvement and implementation of interactive education in the learning process, which can also be attributed to innovative technologies, the author E.A. Karpenko [11].

Interactive methods are modern pedagogical teaching methods, based on the interaction of students between themselves and the teacher, moreover with sharing, and the emphasis of activity is consciously shifted from the teacher to the student.

Interactive learning, being a consistent activity aimed at mastering the world around us, when using interactive educational technologies, presupposes a different educational process logic than usual: not from theory to practice, but from acquiring new experience to awareness. Purpose of application: implementation in the future in the practical activities of the subject. 
Interactive teaching methods allow you to put the acquired knowledge into activity and form a number of necessary competencies in solving practical problems from moral and spiritual to professionally important and necessary. The productivity of this approach is ensured by increasing interest, activating personal resources and deeply immersing students in the educational process. With the regular use of interactive learning tools, forms and methods, professional interest is consolidated, accompanied by a motivation to learn, a need is formed to acquire new knowledge and put it into practice, a desire to be involved in solving the problems discussed, which is very necessary for students who do not adapt well in the new team, for individuals with increased anxiety and low stress resistance.

Advantages of interactive learning:

1. Interactive learning develops original thinking, contributes to the improvement of behavioral characteristics, including the ability to communicate, to show their individuality.

2. Increased motivation may be due to the use of interactive methods due to their unusualness, creativity and diversity.

3. Interactive teaching methods provide psychological comfort for the student's personality, without causing "information starvation" or "information obesity". The student, using the knowledge gained, organizes his educational activities himself, supplementing the volume of knowledge with the results of an independent cognitive search. Case studies, practical tasks can improve the learning process due to the active inclusion of the student, and while there is no negative assessment, anti-stress strategies are formed that are the foundation for the emergence of stress resistance, which will be discussed below.

Interactive learning develops the ability to solve the problem in many ways, including extraordinary, to set a strategic goal and achieve it with the help of psychological and pedagogical methods, for example, modeling.

As a result of the use of interactive learning, the student involuntarily begins to reflect, gets a new experience of communication in the environment of subject-subject interaction, the development of communicative skills, overcomes psychological barriers, thereby strengthening his personal potential [12].

Therefore, one of the components of the theoretical psychological and pedagogical model is interactive learning.

\section{Methodology}

A model is an artificial project for studying a phenomenon, a process, a kind of theoretical algorithm of a practical process. Didactic principles imply the possibility of modeling not only the content of education, but also educational activities. The need to master the modeling technique is associated both with the general method of scientific knowledge and with psychological and pedagogical paradigms. Modeling can be represented as an educational tool, and a way to control students' knowledge, and a generalization of educational material [13-15].

Modeling is widely applicable in the creation of pedagogical systems. So we can offer a number of successive stages:

1) identification of the object of study;

2) summation of knowledge about the object;

3) an explanation of the need for modeling;

4) selection of existing variables and postulates.

When applying modeling in pedagogy, the presentation of educational information occurs in a visual form. A training model is identified that can be defined as a pedagogical technique, a system of methods and organizational forms of training that make up the didactic basis. 
The model acts as an analogue of the original object, but there is no complete identity. The degree to which the model matches the original object is an important indicator of the completeness and truth of the theory with which the model was created.

Define the requirements for pedagogical modeling:

1) similarity, but not identity with the original object;

2) information proximity with the subject-subject interaction;

3) the prospects of performance in the educational process;

4) the possibility of further development and additions;

5) implementation in the educational space;

6) the creation of curricula and general education programs taking into account the psychological-acmeological model;

7) focus on the development of personality determinants.

Next, we give examples of structural models obtained by the author of the article in the framework of psychological and pedagogical research.

To identify the individual and personal determinants of the future specialist in the digital space, to increase his motivation for learning activities for the purpose of quality training, we propose a theoretical psychological and pedagogical model that includes the following components: interactive learning, positive factors (contributing to the development of positive educational motivation), negative factors, (preventing the development of positive motivational activity), "I-image", the development of needs, the basic properties of nervous system theme.

Interactive Learning Block:

1) independence of choice of forms, methods, means of solving the problem;

2) an individual-personal approach, taking into account ethno-confessional characteristics;

3) independence and creativity in choosing a solution to the task;

4) psychological comfort in teamwork;

5) the positive interaction of the teacher and student;

6) the adequacy of evaluating the results of educational activities.

Block "Positive factors":

1) cognitive interest;

2) introspection;

3) reflection;

4) social interest;

5) trusting subject-subject relations;

6) active participation in student life;

7) participation in the preparation of interactive classes;

8) the manifestation of leadership qualities and personality, pragmatic interest, professional ethical and status interests.

Block "negative factors":

1) lack of interest in the studied disciplines due to improper professional choice, communicative incompetence;

2) accentuated character traits;

3) lack of interest in the subject under study due to the formality of teaching;

4) lack of assessment of student activity, misunderstanding of the application of the studied subject in practical activities.

The "I" - image block includes the following components:

1) internalization;

2) strategic planning of educational activities;

3) psychological adaptation to changing conditions;

4) active independent work; 
5) improving interpersonal relationships;

6) focus on the dynamics of professions in the labor market, the development of creativity.

The block "Development of needs" includes components:

1) approval of value-semantic guidelines;

2) the correctness of professional choice;

3) existentiality;

4) expression of will.

The "Basic properties of the nervous system" block includes:

1) the strength of the nervous processes;

2) features of motor reaction;

3) reactivity and activity in decision making

4) type of temperament;

5) stress resistance.

All the blocks of the psychological and pedagogical model are a theoretical tool, but can be applied in the educational process when teaching any discipline, in the implementation of general cultural and professional competencies. In our opinion, one of the competencies required on the labor market is stress tolerance, which includes such components as emotionality, sensuality, anxiety, and anxiety.

In order to study the factors for identifying stress resistance in educational activities, we compiled a questionnaire "Factors and conditions of stress resistance of second-year students." The respondents were second-year students of the Faculty of Technology of the Voronezh State University of Engineering Technologies in the amount of 100 people. Gender differences were not taken into account. Statistical data processing and Varimax rotation highlighted the following factors:

1) socio-psychological;

2) behavioral;

3) subjective

4) physiological;

5) organizational.

The above factors with an average weight load are shown in figure 1.

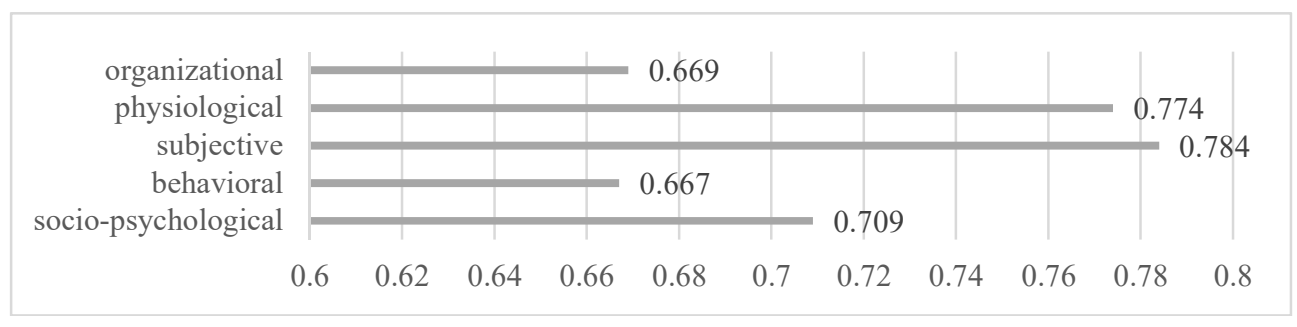

Fig. 1. "Factors of resistance of second year students".

The first "socio-psychological" factor with a significant weight load included the components "microclimate in the study group" (0.811), "adaptation in the new team" (0.768), "position in the student team" (0.752), "positive subject-subject relations "(0.745)," satisfaction with the professional choice made "(0.710)," the novelty of the training system "(0.690)," participation in the preparation of interactive classes "(0.674)," professional reflection "(0.525), etc. Similar manifestations were grouped into this factor, since it meant lich motivation student spine contained Signs of active learning activities and the formation of professional consciousness.

The second factor, called "behavioral", included "leadership qualities" (0.825), "satisfaction with one's success" (0.645), "unproductiveness" (0.610), "good luck 
anticipation" (0.590), and other similar manifestations. grouped into this factor, as it meant situational anxiety of the student's personality and contained signs of impaired activity.

"Subjective factor" was the content of the third factor. It included "temperament properties" $(0.910)$, "self-awareness and self-acceptance" $(0.891)$, "sensitivity to criticism" (0.892), "communication skills" (0.884), "motivation" (0.860), "planning of educational activities" ( 0.815$)$, "active independent work" $(0.730)$, "level of personal self-regulation" (0.724), "possession of psycho-regulatory technologies of behavior" (0.690); "Locus of control" (0.678), "coping strategies in situations of uncertainty" (0.546), etc.

The "physiological factor" was naturally identified as the fourth factor, which reduced personality potential and stress resistance. This factor included such components as "lack of time" (0.910), "lack of rest" (0.811), "insomnia" (0.730), "somatic pain" $(0.690)$, "apathy" $(0.580)$, etc.

The components of the fifth factor, "organizational" were "judgments about one's own problems in knowledge" $(0.761)$, "attitude to the learning system" $(0.756)$, "interest in the subjects studied" (0.641), "lack of social skills" (0.612), "impossibility structure time" (0.574), etc. The data is shown in the table 1 .

Thus, factors were identified, the components of some of them were negative and showed that some respondents have a high tendency to stress, increased anxiety, which negatively affects the level of students' personal maturity, contributes to a decrease in motivation and is an obstacle to mastering competencies.

Table 1. "Factors of resistance of second year students".

\begin{tabular}{|c|c|c|}
\hline $\begin{array}{l}\text { Factors of stress } \\
\text { resistance }\end{array}$ & Factor components & Weight load \\
\hline \multirow{8}{*}{ socio-psychological } & microclimate in the study group & 0.811 \\
\hline & adaptation in a new team & 0.768 \\
\hline & position in the student team & 0.752 \\
\hline & positive subject-subject relationships & 0.745 \\
\hline & satisfaction with the professional choice made & 0.710 \\
\hline & novelty of the training system & 0.690 \\
\hline & participation in the preparation of interactive classes & 0.674 \\
\hline & professional reflection & 0.525 \\
\hline \multirow{4}{*}{ behavioral } & leadership skills & 0.825 \\
\hline & satisfaction with your success & 0.645 \\
\hline & unproductiveness & 0.610 \\
\hline & anticipation of good luck & 0.590 \\
\hline \multirow{11}{*}{ subjective } & properties of temperament & 0.910 \\
\hline & self-awareness and self-acceptance & 0.891 \\
\hline & sensitivity to criticism & 0.892 \\
\hline & communication skills & 0.884 \\
\hline & motivation & 0.860 \\
\hline & planning of educational activities & 0.815 \\
\hline & active independent work & 0.730 \\
\hline & level of personal self-regulation & 0.724 \\
\hline & possession psychosuggestive technology behavior & 0.690 \\
\hline & locus of control & 0.678 \\
\hline & coping strategies in a situation of uncertainty & 0.546 \\
\hline \multirow{5}{*}{ physiological } & lack of time & 0.910 \\
\hline & lack of rest & 0.811 \\
\hline & insomnia & 0.730 \\
\hline & somatic pain & 0.690 \\
\hline & apathy & 0.580 \\
\hline organizational & judgments about your own problems in knowledge & 0.761 \\
\hline
\end{tabular}




\begin{tabular}{|l|l|c|}
\hline & attitude to the training system & 0.756 \\
\cline { 2 - 3 } & interest in the subjects studied & 0.641 \\
\cline { 2 - 3 } & lack of social skills & 0.612 \\
\cline { 2 - 3 } & inability to structure time & 0.574 \\
\hline
\end{tabular}

Socio-psychological adaptation of the educational process to the needs of the student's personality, focus on the person's active development of cognitive methods and a practiceoriented approach, attention to individual expressions of interest and abilities, taking into account the desire for learning, providing opportunities for self-disclosure of personality are all relevant features of modern learning.

And pedagogy will purposefully study the issues of structuring, modernizing the educational process, propose forms and methods, means of implementing projects.

In Russia, the modeling methodology is determined by the work of the scientific communities of mathematicians, programmers, computer scientists and specialists in the fields of the humanities and social sciences, leading their activities, including in online communities. Therefore, special training is needed for teaching staff who are ready to study in the field of mathematical modeling and databases. This implies the need for the introduction of relevant specializations and special courses at university departments, advanced training of scientific and pedagogical personnel, the development of teaching and methodological manuals. Innovative training stimulates an active search for teacher knowledge and its transfer to students, traditional teaching methods are replaced by more relevant and necessary in the digital economy, the number of competencies and the need for their use in the labor market are increasing. The nature of training, as well as the nature of personality, has the ability to change and transform under the influence of modern megatrends, the tasks for a university teacher are complicated in the context of socioeconomic changes.

\section{Conclusion}

Thus, modeling in pedagogy is a resource tool for the modernization of the pedagogical process, algorithms the direction of the teacher's efforts to implement the goals of the activity: educational, developing, educational. It represents a structured matrix, which clearly demonstrates in which block of the theoretical model the solution of a certain pedagogical problem is possible, where the development of general cultural and professional competencies is most effective. A number of researchers come to the conclusion that pedagogical modeling is a promising breakthrough in the didactic plan, but the definition itself implies numerous opinions. So, N. A Kozyrev [16] suggests that "pedagogical modeling is a method of scientific and pedagogical research, which determines the possibility of the emergence of new, high-quality knowledge or tools in the system of determination, visualization, optimization and solving multicultural and intrapersonal contradictions of professional pedagogical activity". In our opinion, a fairly accurate and relevant definition. It should be noted and modeling functions in the pedagogical process:

1) descriptive - a generalization of previous pedagogical experience with the inclusion of rationalizations and innovations;

2) prognostic - the construction of more advanced models, taking into account changes in socio-economic requirements;

3) technological - implementation of the proposed rationalizations and innovations in the pedagogical process;

4) integrative - purposeful systemic interaction of theory and practice. 


\section{References}

1. F. Kirguyev, Modern problems of science and education 3, 348-354 (2015)

2. I. Kiseleva, Proceedings of the Voronezh State University of Engineering Technologies 81(1), 402-411 (2019)

3. M. Yadrovskaya, Bulletin of Tomsk State University 366, 139-143 (2013)

4. N. Lee, Tojet 10, 156 (2011)

5. N. Bakhmudkadiev, Problems and prospects for the development of education: proceedings of the III International Scientific Conference, 116-118 (2013)

6. N. Kobzeva, Young Scientist 5, 142-144 (2011)

7. V. Yatsenko, The role of psychology and pedagogy in the development of society: collection of articles of the International scientific and practical conference, 83-85 (2015)

8. M. Khutornaya, Scientific and Psychological School. Results of the 20th anniversary of TSU named after G.R. Derzhavin, proceedings of the seventh International Seminar of Young Scientists and Graduate Students, 133-136 (2015)

9. M. Klarin, Innovative Education, Conceptual and Practical Challenges, Monograph (2015)

10. P. Efimov, Integration of Education 2, 16-21 (2015)

11. E. Karpenko, Pedagogy of the new time. Publishing Solutions 104 (2017)

12. I. Kotlyarova, Bulletin of the South Ural State University. Series: Education. Pedagogical sciences 3(11), 6-10 (2019)

13. N. Yaroslavtseva, Prospects for Science and Education 3(39), 55-72 (2019)

14. N. Romashevskaya, Psychology, Sociology and Pedagogy 4, 56-60 (2016)

15. N. Matyash, Psychological research: electron. scientific Zh. 3(17), 23-26 (2011)

16. N. Kozyrev, Modern Pedagogy 8, 36-39 (2015) 